\title{
Effect of ZnO Nanoparticles on Brassica nigra Seedlings and Stem Explants: Growth Dynamics and Antioxidative Response
}

\author{
Hira Zafar ${ }^{1}$, Attarad Ali ${ }^{1}$, Joham S. Ali', Ihsan U. Haq ${ }^{2}$ and Muhammad Zia ${ }^{1 *}$ \\ ${ }^{1}$ Department of Biotechnology, Quaid-i-Azam University, Islamabad, Pakistan, ${ }^{2}$ Department of Pharmacy, Quaid-i-Azam \\ University, Islamabad, Pakistan
}

\section{OPEN ACCESS}

Edited by:

Shabir Hussain Wani,

Sher-e-Kashmir University

of Agricultural Sciences

and Technology of Kashmir, India

Reviewed by:

Fayyaz Muhammad Chaudhary,

Preston University, Pakistan

Mubarak Ali

GSI Helmholtzzentrum für

Schwerionenforschung/Technische

Universität Darmstadt, Germany

*Correspondence:

Muhammad Zia

ziachaudhary@gmail.com

Specialty section:

This article was submitted to

Plant Biotechnology,

a section of the journal

Frontiers in Plant Science

Received: 16 February 2016

Accepted: 04 April 2016

Published: 20 April 2016

Citation:

Zafar H, Ali A, Ali JS, Haq IU

and Zia M (2016) Effect of ZnO

Nanoparticles on Brassica nigra Seedlings and Stem Explants: Growth

Dynamics and Antioxidative

Response. Front. Plant Sci. 7:535.

doi: $10.3389 /$ fpls.2016.00535
Nanoparticles (NPs) have diverse properties when compared to respective chemicals due to their structure, surface to volume ratio, morphology, and reactivity. Toxicological effects of metallic NPs on organisms including plants have been reported. However, to the best of our knowledge, there is still not any report on the effect of NPs on in vitro culture of plant explants. In this study, ZnO NPs concentration ranging from 500 to $1500 \mathrm{mg} / \mathrm{L}$ adversely affects the Brassica nigra seed germination and seedling growth and also lead to an increase in the antioxidative activities and non-enzymatic antioxidants. While, culturing the stem explants of $B$. nigra on Murashige and Skoog (MS) medium at lower concentration of ZnO NPs (1-20 mg/L) resulted in the production of white thin roots with thick root hairs. At $10 \mathrm{mg} / \mathrm{L} \mathrm{ZnO} N P s$, shoots emergence is also observed. The developed calli/roots showed 79\% DPPH (2,2-diphenyl-1-picryl hydrazyl) radical scavenging activity at $10 \mathrm{mg} / \mathrm{L}$. The total antioxidant and reducing power potential also significantly affected in presence of $\mathrm{ZnO}$ NPs. Moreover, an increase in non-enzymatic antioxidative molecules, phenolics (up to $0.15 \mu \mathrm{g}$ GAE/mg FW) and flavonoids (up to $0.22 \mu \mathrm{g}$ QE/mg FW), depending on NPs concentration is also observed. We conclude that ZnO NPs may induce roots from explants cultured on appropriate medium that can be used for production of valuable secondary metabolites.

Keywords: antioxidative activities, Brassica nigra, callus, nanoparticles, rooting, shooting, ZnO

\section{INTRODUCTION}

Metallic nanoparticles (NPs) are now frequently used in industries for variety of applications. However, their release in environment makes them a threatening agent to living organisms in a way of toxicity. The toxic effects are due to size, surface area ratio, morphology, nature, composition, reactivity, and others (Zaka et al., 2016). Although NPs of toxic elements are supposed to be more toxic but less or least toxic elements are also proven toxic when switched to NPs. Engineering methodology and post processing of NPs alter the physico-chemical properties and reactivity. The toxicity of metal oxide NPs involves three distinct mechanisms; (i) release of respective metal ion; (ii) surface modification and interaction with media; (iii) disruption biomolecules (Brunner et al., 2006).

Among various metals, zinc $(\mathrm{Zn})$ plays vital role in biochemical, physiological and anatomical responses but below to threshold level. Zinc oxide $(\mathrm{ZnO}) \mathrm{NPs}$ are widely used in paints, coating 
materials, medical and personal care products, and many more. $\mathrm{ZnO}$ NPs are also used as UV protector and absorber material. Beside their potential use, it has increased environmental and health risks due to their interaction with biological and chemical materials (Chithrani et al., 2006). The production of $\mathrm{ZnO}$ NPs is up to 528 tons/year and there is increase in production and utilization with time (Zhang and Saebfar, 2010). Increased use in industrial products has led their release in environment, i.e., from cosmetic products, sunscreens and others (Danovaro et al., 2008). There are limited studies reported on phytotoxicity of $\mathrm{ZnO}$ nanoparticles on plants. Some plant species, i.e., rape, corn, lettuce, radish, ryegrass, cucumber (Lin and Xing, 2007), zucchini (Stampoulis et al., 2009), garden cress, and broad bean (Manzo et al., 2011), and wheat (Du et al., 2011) are sensitive toward $\mathrm{ZnO}$ NPs. Presence of ZnO NPs in surrounding environment affect plant architecture, physiology and biochemistry. The toxicity is considered due to internalization of NPs, accumulation in root tissue and root surface, dissolution of zinc ions from NPs along with other physio chemical properties (Ma et al., 2009, 2011).

Brassica species are wild and also grown as food and fodder crops. Brassica nigra is commonly grown for oil extraction, animal cake production, and green manure. It is considered tolerant to heavy metals (Angelova and Ivanov, 2009) and also known as metal accumulators and potential phytoextraction (Van Ginneken et al., 2007). Based on resistivity and tolerance toward nanoparticles, $B$. nigra could be considered as a model plant to study reaction mechanisms of metallic nanoparticles on plant growth.

From an ecological perspective, understanding the $\mathrm{ZnO}$ NPs toxicity toward environmentally relevant plant species is of great importance. The aim of this study is to determine the toxicity of $\mathrm{ZnO}$ nanoparticles on $B$. nigra including its seed germination; seedling growth and antioxidative response. Moreover, stem explants cultured in the presence of ZnO NPs in MS medium is used to determine the response of undifferentiated mass of cells. We believe that the experimental results would contribute to the enrichment of knowledge pertaining to the interactions of $\mathrm{ZnO}$ NPs with plant system.

\section{MATERIALS AND METHODS}

\section{Materials}

All the chemicals and reagents were purchased from SigmaAldrich and Merck. MS media was acquired from Phytotech. $\mathrm{ZnO}$ NPs were synthesized by co-precipitation method (reported elsewhere). The NP diameter $(<100 \mathrm{~nm})$ is determined through scanning electron microscopy.

\section{Effect of ZnO NPs on B. nigra Seed Germination and Growth Preparation of $\mathrm{ZnO}$ Supplemented Media}

To investigate toxicity of $\mathrm{ZnO}$ NPs, plain agar media was used. Briefly, ZnO NPs were suspended at 0 (control), 500, 1000, and $1500 \mathrm{mg} / \mathrm{L}$ in distilled autoclaved water. Sucrose was added at $3 \%$ as carbon source. To avoid aggregation of NPs, the medium was sonicated for $30 \mathrm{~min}$. The $\mathrm{pH}$ was adjusted to 5.8 and agar
$(0.7 \%)$ was added as solidifying agent. Agar was dissolved by heating. The medium was dispensed as $30 \mathrm{ml} / 100 \mathrm{ml}$ in a conical flask after thorough shaking. The media was autoclaved at $121^{\circ} \mathrm{C}$, 15 psi pressure for $20 \mathrm{~min}$. To avoid agglomeration or settling of NPs at the base, the medium was allowed to cool up to $45^{\circ} \mathrm{C}$; shacked well and the flasks were kept at $-4^{\circ} \mathrm{C}$ till solidification.

\section{Seed Inoculation and Growth Observation}

Brassica nigra seeds were obtained from National Agriculture Research Council (NARC) Islamabad Pakistan with germination efficiency $>98 \%$. Under aseptic conditions, the seeds were treated with $0.1 \%$ mercuric chloride $(\mathrm{w} / \mathrm{v})$ for $2-3 \mathrm{~min}$, followed by thorough rinsing with sterilized distilled water. Four seeds were inoculated in each flask and five flasks for each concentration were prepared. The flasks were kept in growth chamber at $25^{\circ} \mathrm{C}$ in dark. The germination efficiency was observed at 5 th day of seed inoculation thereafter the flasks were transferred to $16 / 8$ light dark cycle for additional 7 days. At the end of experiment plants were isolated and analyzed for shoot, root length, and fresh weight (FW). The plant parts were dried under vacuum at $45^{\circ} \mathrm{C}$ for $48 \mathrm{~h}$ to calculate dry biomass.

\section{Effect of ZnO NPs on Stem Explant Culture \\ Media Preparation}

Murashige and Skoog (1962) media was used as basal medium. $\mathrm{ZnO} \mathrm{NPs}(0,1,5,10$, and $20 \mathrm{mg} / \mathrm{l})$ were supplemented in MS media along with $3 \%$ sucrose. $\mathrm{pH}$ was adjusted at 5.8 and media was sonicated for $30 \mathrm{~min}$ to avoid aggregation of NPs. Agar $(0.7 \%)$ was added and dissolved by heating. The media was dispensed as $30 \mathrm{ml} / 100 \mathrm{ml}$ in a conical flask with thorough shaking. Then autoclaved at $121^{\circ} \mathrm{C}, 15$ psi pressure for $20 \mathrm{~min}$. To avoid agglomeration or settling of NPs at the base, the media was allowed to cool up to $45^{\circ} \mathrm{C}$; shacked well and flasks were kept at $-4^{\circ} \mathrm{C}$ till solidification.

\section{Explant Source and Growth Conditions}

The 14 days old $B$. nigra plants grown on plain agar medium were used as explants source. Under aseptic conditions, stem was separated and cut into $8 \mathrm{~mm}$ pieces as explants and inoculated on the surface of media. The flasks were incubated at $25^{\circ} \mathrm{C}$ and $16 / 8$ light dark period in growth room. The test was performed in triplicate; each replicate contained 10 explants. Data were recorded after 30 days of inoculation and FW and dry weight (DW) were measured.

\section{Preparation of Extracts and Determination of Antioxidative Potential}

The dried plant materials were ground in mortar and pestle and suspension was prepared in DMSO at $100 \mathrm{mg} / \mathrm{ml}$ in eppendorf tubes. The tubes were kept at room temperature for $48 \mathrm{~h}$ and centrifuged at $5000 \mathrm{rpm}$ for $3 \mathrm{~min}$. The supernatant was used for estimation of antioxidative activities (DPPH based free radical scavenging activity, total antioxidant potential, total reducing power) and non-enzymatic antioxidants (phenolics and flavonoids). 


\section{Determination of Free Radical Scavenging Potential}

2,2-diphenyl-1-picryl hydrazyl (DPPH) reagent was employed for the determination of free radical scavenging activity (Rehman et al., 2014). Briefly, $10 \mu \mathrm{L}$ of extract was mixed with $190 \mu \mathrm{L}$ of DPPH $(0.004 \% \mathrm{w} / \mathrm{v}$ in methanol). The reaction mixture was incubated in dark for $1 \mathrm{~h}$. The optical density was measured at $515 \mathrm{~nm}$ using microplate reader. Ascorbic acid was employed as positive standard, while DMSO as negative control. Percent inhibition was calculated by the following formula:

$$
\begin{aligned}
\text { Percent inhibition of the test sample } & =\% \text { scavenging activity } \\
& =\left(1-\mathrm{Ab}_{\mathrm{s}} / \mathrm{Ab}_{\mathrm{c}}\right) \times 100 .
\end{aligned}
$$

Where $\mathrm{Ab}_{s}$ is the absorbance of DPPH solution with sample, and $\mathrm{Ab}_{\mathrm{c}}$ indicates the absorbance of negative control (containing the reagent and solvent only).

\section{Determination of Total Antioxidant Capacity (TAC)}

Total antioxidant activity of extracts was evaluated by method modified by Fatima et al. (2015). An aliquot of $100 \mu \mathrm{L}$ from stock solution of each extract was mixed with $900 \mu \mathrm{L}$ reagent solutions comprising of $0.6 \mathrm{M}$ sulfuric acid, $4 \mathrm{mM}$ ammonium molybdate and $28 \mathrm{mM}$ sodium phosphate. The reaction mixtures were incubated at $95^{\circ} \mathrm{C}$ for $90 \mathrm{~min}$ followed by cooling at room temperature and absorbance was measured at $695 \mathrm{~nm}$ by using microplate reader. DMSO $(100 \mu \mathrm{L})$ in place of test samples was used as control. For calibration curve, ascorbic acid was used as positive control. The resultant TAC was expressed as $\mu \mathrm{g}$ ascorbic acid equivalent per mg FW ( $\mu$ g AAE/mg FW).

\section{Determination of Total Reducing Power (TRP)}

The reduction potential was investigated according to previously described procedure (Haq et al., 2010). Briefly, $100 \mu \mathrm{L}$ of each sample was mixed with $200 \mu \mathrm{L}$ of phosphate buffer $(0.2 \mathrm{M}, \mathrm{pH}$ 6.6) and $250 \mu \mathrm{L}$ of $1 \% \mathrm{w} / \mathrm{v}$ potassium ferricyanide. The resulting mixture was incubated for $20 \mathrm{~min}$ at $50^{\circ} \mathrm{C}$. After that, the reaction was acidified with $200 \mu \mathrm{L}$ of $10 \% \mathrm{w} / \mathrm{v}$ trichloroacetic acid. The resultant mixtures were centrifuged at $3000 \mathrm{rpm}$ for $10 \mathrm{~min}$ and supernatant layer $(150 \mu \mathrm{L})$ was mixed with $50 \mu \mathrm{L}$ of $0.1 \%$ $\mathrm{w} / \mathrm{v}$ ferric chloride solution and optical density was measured at $630 \mathrm{~nm}$. Ascorbic acid was maintained as positive control and results were expressed as $\mu \mathrm{g}$ ascorbic acid equivalent per mg FW ( $\mu \mathrm{g}$ AAE/mg FW).

\section{Determination of Total Phenolic Contents (TPC)}

The total phenolic contents were determined using standard protocol (Haq et al., 2010). In brief, $20 \mu \mathrm{l}$ of extract prepared in DMSO was transferred to each well of 96 well plate. Ninety microliter of Folin-Ciocalteu reagent was added to each well and after five min $90 \mu \mathrm{l} \mathrm{Na} \mathrm{CO}_{3}\left(7.5 \% \mathrm{w} / \mathrm{v}\right.$ in $\left.\mathrm{H}_{2} \mathrm{O}\right)$ was mixed in each well. The reaction mixtures were incubated for $1 \mathrm{~h}$ and absorbance was measured at $650 \mathrm{~nm}$ by using microplate reader (Bioteck, USA). Blank (DMSO) and standard (gallic acid in DMSO) were run simultaneously as control. A calibration curve $\left(y=0.0135 \mathrm{x}+0.0846, R^{2}=0.986\right)$ was obtained in parallel under the same operating conditions using gallic acid $(6.25-50 \mu \mathrm{g} / \mathrm{mL})$. The resultant TPC was determined as $\mu \mathrm{g}$ gallic acid equivalent per mg FW ( $\mu$ g GAE/mg FW).

\section{Determination of Total Flavonoid Content (TFC)}

Total flavonoid contents were determined according to the method previously described by Haq et al. (2010). Aliquot of each extract $(20 \mu \mathrm{L})$ was mixed with $10 \mu \mathrm{L}$ of aluminum chloride $(10 \%$ $\mathrm{w} / \mathrm{v})$ and $10 \mu \mathrm{L}$ of potassium acetate $(1 \mathrm{M})$ solutions. Thereafter distilled water was added to get a final volume of $200 \mu \mathrm{L}$. After 30 min of incubation; absorbance was measured by using microplate reader (Bioteck, USA) at $415 \mathrm{~nm}$. The calibration curve $\left(y=0.0269 \mathrm{x}+0.00765, R^{2}=0.998\right)$ was drawn by using quercetin as standard at 0 to $40 \mu \mathrm{g} / \mathrm{mL}$ and the flavonoid content were established in $\mu \mathrm{g}$ quercetin equivalent per mg FW ( $\mu \mathrm{g}$ $\mathrm{QE} / \mathrm{mg} \mathrm{FW})$.

\section{Statistical Analysis}

To investigate effect of NPs on B. nigra seed germination and plant characters; five flasks of each concentration were inoculated, each containing four seeds. To analyze explant response, 30 stem explants were cultured on MS medium. The results are presented as mean with standard error. All antioxidative tests were performed in triplicate. The means were further analyzed using analysis of variance (ANOVA) and least significant difference (LSD).

\section{RESULTS}

\section{Effect of ZnO NPs on B. nigra Growth and Antioxidative Response}

The presence of $\mathrm{ZnO}$ NPs in the culture media significantly inhibited germination of $B$. nigra seeds. Increase of NPs concentration decreased germination efficiency recorded on 5th day of seed inoculation (Table 1). $\mathrm{ZnO}$ NPs in the culture media generated stimulatory effect on shoot growth but inhibited root length. At $500 \mathrm{mg} / \mathrm{L} \mathrm{ZnO}, 64 \%$ increase in shoot length was observed compared to control, while at the same concentration $61 \%$ reduction in root length was observed (Table 1; Figure 1). Although, there was positive effect on shoot lengths but shoot FW decreased by increasing the NPs in the media, due to reduction in diameter of stem. At $1500 \mathrm{mg} / \mathrm{L}$ NPs, 21\% reduction in shoot FW was observed. Comparatively root FW significantly decreased; $73 \%$ at $500 \mathrm{mg} / \mathrm{L}$ and $87 \%$ at $1500 \mathrm{mg} / \mathrm{L}$. The shoot DW did not show any significant change at 500 and $1000 \mathrm{mg} / \mathrm{L}$ but at $1500 \mathrm{mg} / \mathrm{L}$ boost ( $1.18 \mathrm{mg} ; 51 \%$ increase in comparison with control) was observed.

2,2-diphenyl-1-picryl hydrazyl radical scavenging activity, total antioxidant potential, reducing power potential, total phenolic and flavonoid contents significantly varied in B. nigra shoots and roots on $\mathrm{ZnO}$ NPs exposure (Figure 2). Free radical scavenging activity increased 133 and $6 \%$ in root and shoot, respectively, at $500 \mathrm{mg} / \mathrm{L}$ then decreased at $1000 \mathrm{mg} / \mathrm{L}$ and again a boost was observed at $1500 \mathrm{mg} / \mathrm{L}$. A steady increase in TAC activity was observed both for root and shoots parts. No difference was recorded at $500 \mathrm{mg} / \mathrm{L}$ compared to control, however, $88 \%$ increase in root and $436 \%$ increase in shoot TAC was observed at $1500 \mathrm{mg} / \mathrm{L}$. Significant change in total reducing power potential (TRP) 
TABLE 1 | Effect of CuO NPs on Brassica nigra seed germination, plantlet length and fresh and dry weight at 5th day of seed inoculation.

\begin{tabular}{|c|c|c|c|c|c|c|c|}
\hline \multirow[t]{2}{*}{ Conc. } & \multirow[t]{2}{*}{ Seed germination. } & \multicolumn{2}{|c|}{ Length (cm) } & \multicolumn{2}{|c|}{ Fresh weight (g) } & \multicolumn{2}{|c|}{ Dry weight (g) } \\
\hline & & Shoot & Root & Shoot & Root & Shoot & Root \\
\hline Control & 20 & $3.07 \pm 0.14^{d}$ & $7.81 \pm 0.56^{a}$ & $34.95 \pm 3.9^{a}$ & $4.74 \pm 0.23^{a}$ & $0.78 \pm 0.1^{\mathrm{c}}$ & $0.44 \pm 0.02^{a}$ \\
\hline 500 & 19 & $5.05 \pm 0.2^{\mathrm{a}}$ & $3.03 \pm 0.2^{b}$ & $33.58 \pm 2.4^{a b}$ & $1.25 \pm 0.14^{b}$ & $0.84 \pm 0.1^{b}$ & $0.17 \pm 0.01^{b}$ \\
\hline 1000 & 16 & $4.27 \pm 0.11^{b}$ & $2.11 \pm 0.18^{c}$ & $29.31 \pm 2.8^{b}$ & $0.68 \pm 0.1^{\mathrm{c}}$ & $0.86 \pm 0.1^{b}$ & $0.16 \pm 0.03^{b}$ \\
\hline 1500 & 14 & $3.96 \pm 0.1^{c}$ & $1.91 \pm 0.1^{d}$ & $27.29 \pm 3.5^{b}$ & $0.59 \pm 0.1^{d}$ & $1.18 \pm 0.1^{\mathrm{a}}$ & $0.11 \pm 0.04^{c}$ \\
\hline
\end{tabular}

Alphabets on values represent $L S D$ values at $p<0.05$.

was also observed in roots and shoots (Figure 2). Consistent increase in TRP was recorded in roots with increase of NPs concentration in the media. However, in shoot maximum TRP was recorded at $1000 \mathrm{mg} / \mathrm{L}$ (442\% increase). There was significant variation in TPC in roots. In case of shoots nonsignificant variation was observed at 500 and $1000 \mathrm{mg} / \mathrm{L}$. TFC also significantly varied in roots, however, among shoot TFC non-significant variation was observed at 1000 and $1500 \mathrm{mg} / \mathrm{L}$ concentrations.

\section{Effect of ZnO NPs on Stem Explant Growth and Antioxidative Response}

Stem explants significantly responded at different concentrations of $\mathrm{ZnO}$ NPs incorporated MS medium. Calli induction on hormone free MS media is normal phenomenon as multiplication of cells; the undifferentiated mass. Incorporation of $\mathrm{ZnO}$ NPs in MS media resulted in the emergence of minor roots along with calli, however, root induction response enhanced by increase of $\mathrm{ZnO}$ NPs (Figure 1). The roots are white, thin and covered by thick root hairs. Further it was also observed that the calli mass is decreased by increasing the $\mathrm{ZnO}$ concentration. At $10 \mathrm{mg} / \mathrm{L} \mathrm{ZnO}$, few shoots also emerged from calli; however, it looks like leaf induction. The differentiation of cells into organs and decrease in mass of calli by increasing $\mathrm{ZnO}$ in media resulted in the decrease of FW and DW. Stem explants produced calli on MS medium with FW $49.51 \mathrm{mg}$ and DW $0.83 \mathrm{mg}$ (Table 2). However, when $\mathrm{ZnO}$ was also applied in the medium, FW decreased up to $11.95 \mathrm{mg}$ (75 times reduction) at $1 \mathrm{mg} / \mathrm{L}$. The reduction gradually increased when concentration of $\mathrm{ZnO}$ increased. Same

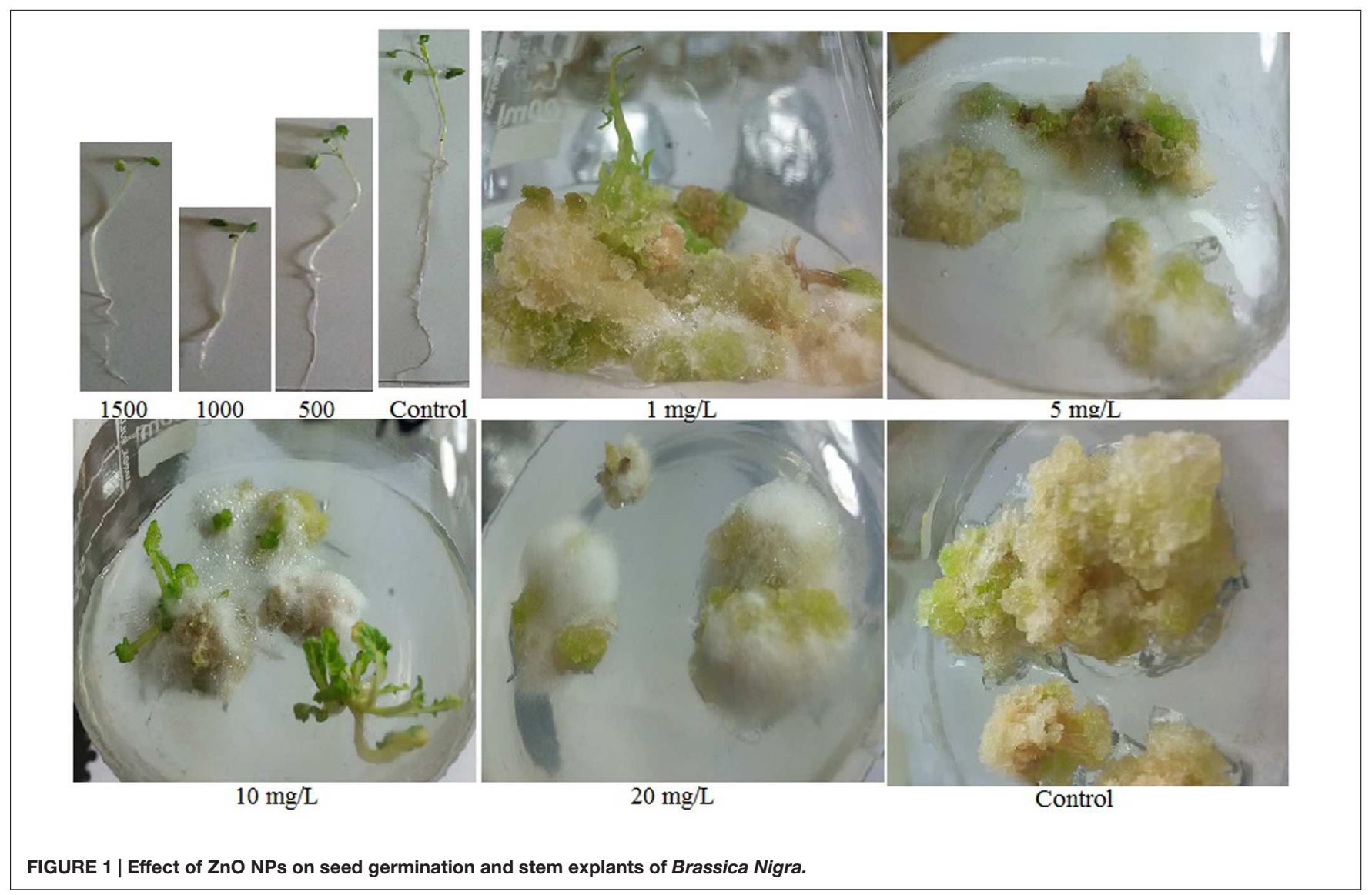




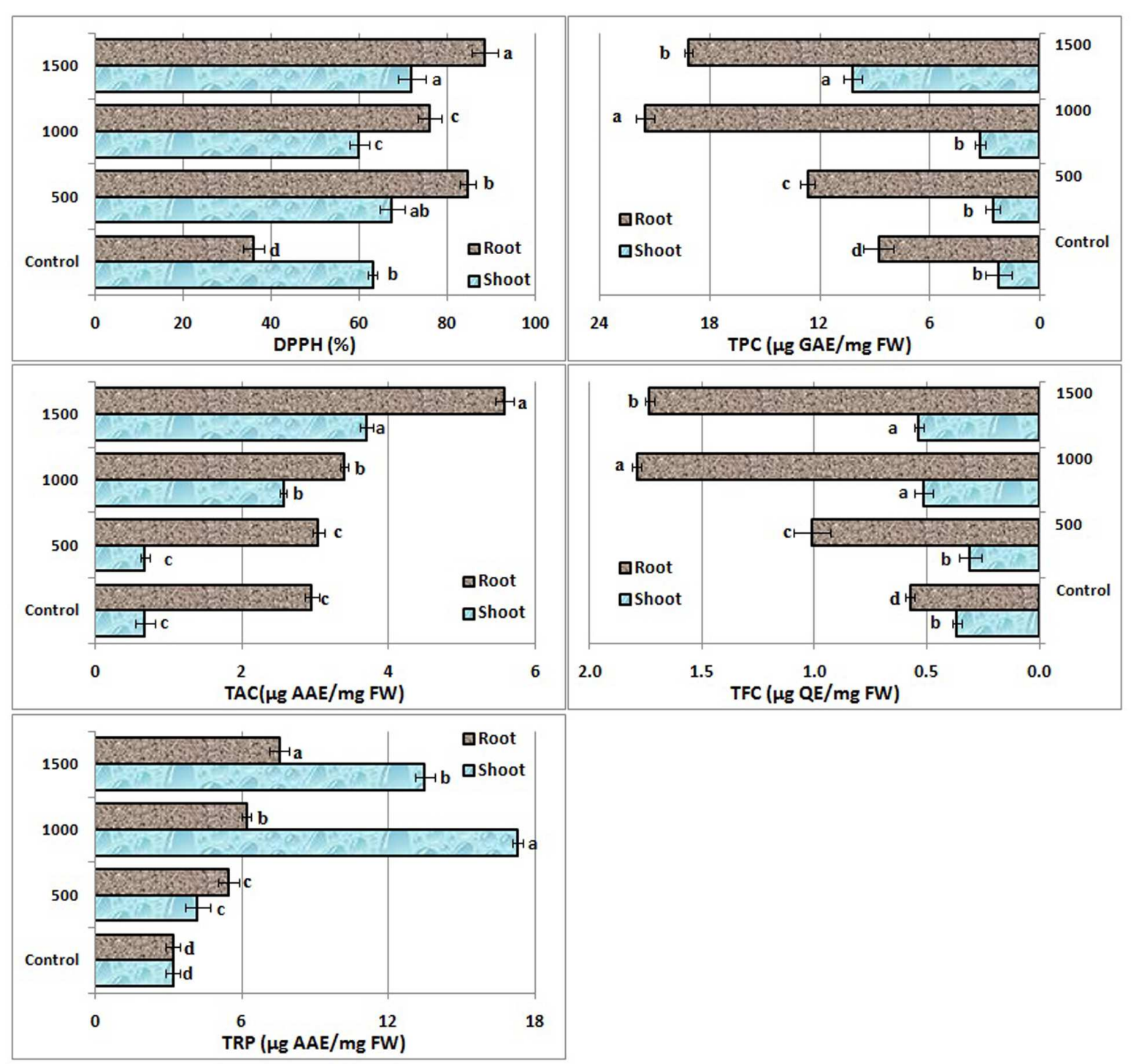

FIGURE 2 | Effect of ZnO NPs on antioxidative response of B. nigra seedlings. Alphabets on bars represent least significant difference (LSD) values at $p<0.05$.

behavior was also observed for DW although DW reduction is less. Only $19 \%$ reduction was observed at $1 \mathrm{mg} / \mathrm{L}$ and it increased up to $63 \%$ at $20 \mathrm{mg} / \mathrm{L}$. Significant variation was also observed in oxidative response (DPPH, TAC, and TRP) and total phenolic and flavonoids (Table 2). Elevated DPPH activity was calculated at all concentrations. At $1 \mathrm{mg} / \mathrm{L} 73 \%$ activity was calculated that reduced at $5 \mathrm{mg} / \mathrm{L}$ and again increased at $10 \mathrm{mg} / \mathrm{L}$. A gradual increase in TAC was observed upto $10 \mathrm{mg} / \mathrm{L}$ but at $20 \mathrm{mg} / \mathrm{L}$ TAC reduced at $0.27 \mu \mathrm{g} \mathrm{AAE} / \mathrm{mg}$ FW. Variation in TRP was observed at different concentrations of $\mathrm{ZnO}$ but all above the control value. Significant variation was also observed in TFC as compared with control but non-significant among the treatments. TPC variably responded in the range of $0.10-$ $0.16 \mu \mathrm{g}$ GAE/mg FW but all above the control value $(0.03 \mu \mathrm{g}$ $\mathrm{GAE} / \mathrm{mg} \mathrm{FW}$ ).

\section{DISCUSSION}

\section{Effect of ZnO NPs on B. nigra Growth and Antioxidative Response}

The relative germination index is extensively used as an indicator of phytotoxicity and root growth is highly sensitive biomarker for phytotoxicity assay (Ali et al., 2015). B. nigra seeds germinated in presence of $\mathrm{ZnO}$ nanoparticles (NPs) showed less germination efficiency but concentration dependent. The inhibition of seed germination might be due to penetration of nano sized particles, aggregation of NPs to micron size, and also dissolution of $\mathrm{Zn}^{+2}$ from $\mathrm{ZnO}$ (Lee et al., 2010). Nutrients along with water might also transports NPs and ions to the intracellular space of seed coat and affects seed germination (Van Dongen et al., 2003). 
TABLE 2 | Effect of ZnO NPs on Brassica nigra stem explants response.

\begin{tabular}{|c|c|c|c|c|c|c|c|}
\hline Conc. (mg/L) & $\begin{array}{c}\text { Fresh weight } \\
\text { (g) }\end{array}$ & Dry weight (g) & DPPH (\%) & $\begin{array}{c}\text { TAC ( } \mu \mathrm{g} \\
\text { GAE/mg FW) }\end{array}$ & $\begin{array}{c}\text { TRP }(\mu \mathrm{g} \\
\text { AAE/mg FW) }\end{array}$ & $\begin{array}{c}\operatorname{TFC}(\mu \mathrm{g} \\
\mathrm{QE} / \mathrm{mg} \mathrm{FW})\end{array}$ & $\begin{array}{c}\text { TPC ( } \mu \mathrm{g} \\
\mathrm{GAE} / \mathrm{mg} \mathrm{FW})\end{array}$ \\
\hline Control & $49.51 \pm 3.8$ & $0.83 \pm 0.21^{a}$ & $28.10 \pm 1^{e}$ & $0.08 \pm 0.01^{d}$ & $0.07 \pm 0.01^{\mathrm{e}}$ & $0.02 \pm 0.0^{d}$ & $0.03 \pm 0.0^{e}$ \\
\hline 1 & $11.95 \pm 1.7^{a}$ & $0.70 \pm 0.2^{b}$ & $73.44 \pm 1.9^{b}$ & $0.27 \pm 0.07^{a}$ & $0.79 \pm 0.13^{a}$ & $0.18 \pm 0.01^{c}$ & $0.16 \pm 0.0^{a}$ \\
\hline 5 & $9.87 \pm 1.9^{b}$ & $0.63 \pm 0.17^{c}$ & $34.26 \pm 1.2^{d}$ & $0.33 \pm 0.09^{c}$ & $0.26 \pm 0.08^{d}$ & $0.21 \pm 0.01^{b}$ & $0.10 \pm 0.0^{d}$ \\
\hline 10 & $7.51 \pm 1.2^{\mathrm{C}}$ & $0.38 \pm 0.11^{d}$ & $79.02 \pm 2.4^{a}$ & $0.53 \pm 0.1^{b}$ & $0.72 \pm 0.24^{b}$ & $0.22 \pm 0.01^{a}$ & $0.14 \pm 0.0^{c}$ \\
\hline 20 & $6.37 \pm 1.1^{d}$ & $0.32 \pm 0.11^{d}$ & $42.06 \pm 2.1^{c}$ & $0.27 \pm 0.03^{a}$ & $0.58 \pm 0.2^{c}$ & $0.21 \pm 0.01^{b}$ & $0.15 \pm 0.0^{b}$ \\
\hline
\end{tabular}

Alphabets on values represent $L S D$ values at $p<0.05$.

Later direct contact of plumule or root with NPs in the media limits growth of root (Wierzbicka and Obidzinska, 1998). The inhibitory effect also depends upon permeability of seed coat for NPs; internalization in root tissues, cytotoxic and genotoxic approaches; and concentration dependency (Kumari et al., 2009, 2011; Ma et al., 2010; Nair et al., 2010).

The increase in shoot length in response of NPs might be nutritional behavior of particles or of dissociated ions but at nonlethal concentration. While, roots are in direct contact with NPs and accumulation in the root tissue or on root surface is cause of shorter root length. The presence of NPs in the agar media also produces negative effect on root elongation because agar media is non-porous, less dissolved oxygen, water logging due to NPs (Langerud and Sandvik, 1987). Lin and Xing (2007) and Manzo et al. (2011) also reported same results for ryegrass and broad bean at higher concentration $(2000 \mathrm{mg} / \mathrm{L})$ while for zucchini no negative effects were observed (Stampoulis et al., 2009). It is presumed that NPs interfere at mitotic cellular division by blocking initiation of prophase (Elghamery et al., 2000). Although shoot length increased in presence of NPs but the shoots were thin and with long inter nodal distance. This might be reason that reduction in shoot FW was observed. The presence of NPs in the culture media did not affect water holding capability of shoots so no significant change in DW was observed. On the other hand, the root FW and DW decreased by increasing NPs concentration. Presence of zinc NPs itself or dissoluted ion interferes with root biochemistry and physiology making variation in length and weight. A number of reports favor these results on root inhibition, i.e., radish, rape, ryegrass, lettuce, cucumber, and Arabidopsis (Lin and Xing, 2007, 2008; Lee et al., 2010). However, inhibitory effect may vary depending on plant species, size and shape of NPs; adherence potential to root surface, translocation capability from root to shoot and dissolution, and release of metallic ions in the surrounding medium (Franklin et al., 2007). Under field conditions wheat reduced biomass by ZnO NPs has been reported (Du et al., 2011). Heavy metals have been widely studied for their inhibitory effect on seed germination, growth, development, biochemical, and physiological processes (Prasad, 2004).

Presence of NPs in the medium induced oxidative stress both in shoots and roots, however, more in root due to direct interaction with NPs. Variations were observed in free radical scavenging response, total antioxidant response and reducing power potential and these parameters are found directly linked with non-enzymatic antioxidative molecules; phenolics and flavonoids. Both, phenolics and flavonoid contents significantly varied in shoots and roots. Few research focus on promotion of oxidative stress in living species on NPs exposure (Wilson et al., 2002; Sayes et al., 2005; Long et al., 2006). The photocatalytic activity of $\mathrm{ZnO}$ also involves in ROS response in organisms because of their band gap energy $3.37 \mathrm{eV}$ (Ma et al., 2009, 2011) though band gap energy is not essential for generation of ROS (Navarro et al., 2008). Although zinc is important element for many metabolic processes but high concentration interferes photosynthesis (Chaney, 1993) and generates oxidative stress (Prasad et al., 1999). It is also important to consider that some NP may generate bioprotective effect against oxidant injury (Chen et al., 2006). Elevated ROS has been observed by ZnO NPs to Allium cepa plants (Kumari et al., 2011).

\section{Effect of ZnO NPs on Stem Explant Growth and Antioxidative Response}

In the presence of $\mathrm{ZnO}$ NPs, stem explant responded differently depending upon concentration of NPs. The control produced green friable calli, while $\mathrm{ZnO}$ induced roots and shoots. AT lower concentration calli produced and some roots also induced from calli. While, at higher concentrations the rooting response was at greater extent. At $10 \mathrm{mg} / \mathrm{L} \mathrm{NPs} \mathrm{few} \mathrm{shoots} \mathrm{also} \mathrm{emerged} \mathrm{that}$ were green but watery. The induction of organ from calli let to reduction in fresh and DW. No report is available on application of NPs on in vitro culture of explant. The induction of roots can be explained in two ways; (i) function of zinc in biochemical process, and (ii) role of ROS. The acidic nature of MS medium may increase dissolution behavior of $\mathrm{ZnO}$ NPs into zinc ion. Where zinc ion functions as cofactor for several enzymes such as oxidases, dehydrogenases, anhydrases, and peroxidases (Hewitt, 1983) and plays role in regulating auxin synthesis, nitrogen metabolism, and cell multiplication (Tsui, 1948; Stanisławski, 1977; Shier, 1994). Cakmak et al. (1989) reported that bean plants provided with sufficient supply of $\mathrm{Zn}$ produced IAA as compared to $\mathrm{Zn}$ deficient plants. This role of zinc has also been observed in tomato and Eucalyptus globulus by applying auxin and $\mathrm{Zn}$ that enhanced root formation (Buczek, 1964; Schwambach et al., 2005). Although, zinc itself regulated the synthesis of endogenous plant hormones; presence of auxin also regulates local synthesis of cytokinin by controlling the expression of adenosine phosphate-isopentenyltransferase (PsIPT) gene, which encodes a key enzyme in cytokinin biosynthesis (Tanaka et al., 2006). Auxin and cytokinin also interact at metabolic level to control plant development and emergence of one part initiate to 
synthesize hormones for opposite one (Nordstrom et al., 2004). On the other hand, ROS generated in explants might also be involved in induction of roots from explant/callus. ROS works as signaling molecule at non-toxic level (Mittler et al., 2004). Furthermore, cellular proliferation upon accumulation of $\mathrm{O}_{2}^{-}$and differentiation upon elevated $\mathrm{H}_{2} \mathrm{O}_{2}$ levels have been reported, i.e., in zebra fish ROS trigger and execute a developmental process (Niethammer et al., 2009). Another aspect of ROS growth regulation involves superoxide, that affects root growth and root hair development (Foreman et al., 2003) through the regulation of calcium channels (Foreman et al., 2003; Jones et al., 2007). Recent reports demonstrated that the concentration of NPs and plant species have significant role defining the toxicity. Sosan et al. (2016) stated that nanoparticles trigger $\mathrm{Ca}^{2+}$ and ROS signaling at cellular level along with other complex physiological modifications at organism level. Furthermore, Hossain et al. (2016) analyzed expression of proteins harboring hormone metabolism, cell organization, signaling, and stress functionalities in soybean on nanoparticles exposure.

\section{CONCLUSION}

In summary, we have experimentally demonstrated the effect of $\mathrm{ZnO}$ NPs concentration on the B. nigra seed germination

\section{REFERENCES}

Ali, A., Phull, A. R., Zia, M., Shah, A. M. A., Malik, R. N., and Haq, I. U. (2015). Phytotoxicity of River Chenab sediments: in vitro morphological and biochemical response of Brassica napus L. Environ. Nanotechnol. Monit. Manag. 4, 74-84. doi: 10.1016/j.enmm.2015.09.003

Angelova, V., and Ivanov, K. (2009). Bioaccumulation and distribution of heavy metals in black mustard (Brassica nigra Koch). Environ. Monit. Assess. 153, 449-459. doi: 10.1007/s10661-008-0370-y

Brunner, T. J., Wick, P., Manser, P., Spohn, P., Grass, R. N., Limbach, L. K., et al. (2006). In vitro cytotoxicity of oxide nanoparticles: comparison to asbestos, silica, and the effect of particle solubility. Environ. Sci. Technol. 40, 4374-4381. doi: 10.1021/es052069i

Buczek, J. (1964). Wpływ 1-tryptofanu na ukorzenianie liści pomidorów. [Effect of tryptophan on rooting of tomato leaves]. Acta Agrobot. 16, 77-85. doi: 10.5586/aa.1964.018

Cakmak, I., Horst, M., and Fritz, B. (1989). Effect of zinc nutritional status on growth, protein metabolism and levels of indole-3-acetic acid and other phytohormones in bean (Phaseolus vulgaris L.). J. Exp. Bot. 40, 405-412. doi: 10.1093/jxb/40.3.405

Chaney, R. L. (1993). "Zinc phytotoxicity," in Zinc in Soil and Plants, ed. A. D. Robson (Dordrecht: Kluwer Academic Publishers), 135-150.

Chen, J., Patil, S., Seal, S., and McGinnis, J. F. (2006). Rare earth nanoparticles prevent retinal degeneration induced by intracellular peroxides. Nat. Nanotechnol. 1, 142-150. doi: 10.1038/nnano.2006.91

Chithrani, B. D., Ghazani, A. A., and Chan, W. C. (2006). Determining the size and shape dependence of gold nanoparticle uptake into mammalian cells. Nano Lett. 6, 662-668. doi: 10.1021/nl052396o

Danovaro, R., Bongiorni, L., Corinaldesi, C., Giovannelli, D., Damiani, E., Astolfi, P., et al. (2008). Sunscreens cause coral bleaching by promoting viral infections. Environ. Health Perspect. 116, 441-447. doi: 10.1289/ehp.10966

Du, W., Sun, Y., Ji, R., Zhu, J., Wu, J., and Guo, H. (2011). TiO2 and ZnO nanoparticles negatively affect wheat growth and soil enzyme activities in agricultural soil. J. Environ. Monit. 13, 822-828. doi: 10.1039/c0em00611d

Elghamery, A. A., Elnahas, A. I., and Mansour, M. M. (2000). The action of atrazine herbicide as an inhibitor of cell division on chromosomes and nucleic acids content in root meristems of Allium cepa and Vicia faba. Cytologia 55, 209-215. and seedling growth. We have also observed that higher NPs concentration led to an increase in the antioxidative activities and non-enzymatic antioxidants. On the other hand, lower concentration of $\mathrm{ZnO}$ NPs resulted in the production of white thin roots with thick root hairs and somewhat shoots from stem explants of $B$. nigra. Moreover, the presence of NPs led to significant effect on total antioxidant and reducing power potential. Based on experimental results we believe that $\mathrm{ZnO}$ NPs may induce roots from explants cultured on appropriate medium that can be used for production of valuable secondary metabolites.

\section{AUTHOR CONTRIBUTIONS}

All authors listed, have made substantial, direct and intellectual contribution to the work, and approved it for publication.

\section{FUNDING}

The authors are thankful to Higher Education Commission Pakistan for partial funding for this research work under Indigenous Scholarship Program.

Fatima, F., Khan, K., Zia, M., Rehman, T. U., Mirza, B., and Haq, I. U. (2015). Extraction optimization of medicinally important metabolites from Datura innoxia Mill.: an in vitro biological and phytochemical investigation. BMC Complement. Altern. Med. 15:376. doi: 10.1186/s12906-015-0891-1

Foreman, J., Demidchik, V., and Bothwell, J. H. (2003). Reactive oxygen species produced by NADPH oxidase regulate plant cell growth. Nature 422, 442-446. doi: $10.1038 /$ nature 01485

Franklin, N. M., Rogers, N. J., Apte, S. C., Batley, G. E., Gadd, G. E., and Casey, P. S. (2007). Comparative toxicity of nanoparticulate $\mathrm{ZnO}$, bulk $\mathrm{ZnO}$, and $\mathrm{ZnCl} 2$ to a freshwater microalga (Pseudokirchneriella subcapitata): the importance of particle solubility. Environ. Sci. Technol. 41, 8484-8490. doi: 10.1021/es071445r

Haq, I. U., Ullah, N., Bibi, G., Kanwal, S., Ahmad, M. S., and Mirza, B. (2010). Antioxidant and cytotoxic activities and phytochemical analysis of Euphorbia wallichii root extract and its fractions. Iran. J. Pharm. Res. 11, 241-249.

Hewitt, E. J. (1983). "Perspective of mineral nutrition: essential and functional metals in plants," in Metals and Micronutrients: Uptake and Utilization by Plants, eds D. A. Robb and W. S. Pierpoint (London: Academic Press), 277-323.

Hossain, Z., Ghazala, M., Katsumi, S., and Setsuko, K. (2016). Insights into the proteomic response of soybean towards $\mathrm{Al} 2 \mathrm{O} 3, \mathrm{ZnO}$, and $\mathrm{Ag}$ nanoparticles stress. J. Hazard. Mater. 304, 291-305. doi: 10.1016/j.jhazmat.2015.10.071

Jones, M. A., Raymond, M. J., Yang, Z., and Smirnoff, N. (2007). NADPH oxidase-dependent reactive oxygen species formation required for root hair growth depends on ROP GTPase. J. Exp. Bot. 58, 1261-1270. doi: 10.1093/jxb/ erl279

Kumari, M., Khan, S. S., Pakrashi, S., Mukherjee, A., and Chandrasekaran, N. (2011). Cytogenetic and genotoxic effects of zinc oxide nanoparticles on root cells of Allium cepa. J. Hazard Mater. 190, 613-621. doi: 10.1016/j.jhazmat.2011.03.095

Kumari, M., Mukherjee, A., and Chandrasekaran, N. (2009). Genotoxicity of silver nanoparticles in Allium cepa. Sci. Total Environ. 407, 5243-5246. doi: 10.1016/j.scitotenv.2009.06.024

Langerud, B. R., and Sandvik, M. (1987). Development of containerized Picea abies (L.) Karst. seedlings grown with heavy watering on various peat, perlite and mineral wool mixtures. New Forests 1, 89-99. doi: 10.1007/BF00030054

Lee, C. W., Mahendra, S., Zodrow, K., Li, D., Tsai, Y. C., and Braam, J. (2010). Developmental phytotoxicity of metal oxide nanoparticles to Arabidopsis thaliana. Environ. Toxicol. Chem. 29, 669-675. doi: 10.1002/etc.58 
Lin, D., and Xing, B. (2008). Root uptake and phytotoxicity of $\mathrm{ZnO}$ nanoparticles. Environ. Sci. Technol. 42, 5580-5585. doi: 10.1021/es800422x

Lin, D. H., and Xing, B. S. (2007). Phytotoxicity of nanoparticles: inhibition of seed germination and root growth. Environ. Pollut. 150, 243-250. doi: 10.1016/j.envpol.2007.01.016

Long, T. C., Saleh, N., Tilton, R. D., Lowry, G. V., and Veronesi, B. (2006). Titanium dioxide (P25) produces reactive oxygen species in immortalized brain microglia (BV2): implications for nanoparticle neurotoxicity. Environ. Sci. Technol. 40, 4346-4352. doi: 10.1021/es060589n

Ma, H., Bertsch, P. M., Glenn, T. C., Kabengi, N. J., and Williams, P. L. (2009). Toxicity of manufactured zinc oxide nanoparticles in the nematode Caenorhabditis elegans. Environ. Toxicol. Chem. 28, 1324-1330. doi: $10.1897 / 08-262.1$

Ma, H., Kabengi, N. J., Bertsch, P. M., Unrine, J. M., Glenn, T. C., and Williams, P. L. (2011). Comparative phototoxicity of nanoparticulate and bulk $\mathrm{ZnO}$ to a free-living nematode Caenorhabditis elegans: the importance of illumination mode and primary particle size. Environ. Pollut. 159, 1473-1480. doi: 10.1016/j.envpol.2011.03.013

Ma, X., Lee, J. G., Deng, Y., and Kolmakov, A. (2010). Interactions between engineered nanoparticles (ENPs) and plants: phytotoxicity, uptake and accumulation. Sci. Total Environ. 408, 3053-3061. doi: 10.1016/j.scitotenv.2010.03.031

Manzo, S., Rocco, A., Carotenuto, R., De Luca, P. F., Miglietta, M., Rametta, G., et al. (2011). Investigation of $\mathrm{ZnO}$ nanoparticles' ecotoxicological effects towards different soil organisms. Environ. Sci. Pollut. Res. 18, 756-763. doi: 10.1007/s11356-010-0421-0

Mittler, R., Vanderauwera, S., Gollery, M., and Van Breusegem, F. (2004). Reactive oxygen gene network of plants. Trends Plant Sci. 9, 490-498. doi: 10.1016/j.tplants.2004.08.009

Murashige, T., and Skoog, F. (1962). A revised medium for rapid growth and bio assays with tobacco tissue cultures. Physiol. Plant. 15, 473-497. doi: 10.1111/j.1399-3054.1962.tb08052.x

Nair, R., Varghese, S. H., Nair, B. G., Maekawa, T., Yoshida, Y., and Kumar, D. S. (2010). Nanoparticulate material delivery to plants. Plant Sci. 179, 154-163. doi: 10.1016/j.plantsci.2010.04.012

Navarro, E., Baun, A., Behra, R., Hartmann, N., Filser, J., Miao, A. J., et al. (2008). Environmental behavior and ecotoxicity of engineered nanoparticles to algae, plants, and fungi. Ecotoxicology 17, 372-386. doi: 10.1007/s10646-008-0214-0

Niethammer, P., Grabher, C., Look, A. T., and Mitchison, T. J. (2009). A tissue scale gradient of hydrogen peroxide mediates rapid wound detection in zebrafish. Nature 459, 996-999. doi: 10.1038/nature08119

Nordstrom, A., Tarkowski, P., Tarkowska, D., Norbaek, R., Astot, C., Dolezal, K., et al. (2004). Auxin regulation of cytokinin biosynthesis in Arabidopsis thaliana: a factor of potential importance for auxin-cytokinin-regulated development. Proc. Natl. Acad. Sci. U.S.A. 101, 8039-8044. doi: 10.1073/pnas.0402504101

Prasad, K. V. S. K., Paradha, S., and Sharmila, P. (1999). Concerted action of antioxidant enzymes and curtailed growth under zinc toxicity in Brassica juncea. Environ. Exp. Bot. 42, 1-10. doi: 10.1016/S0098-8472(99) 00013-1

Prasad, M. N. V. (2004). Heavy Metal Stress in Plants: From Biomolecules to Ecosystems, 2nd Edn. New York, NY: Springer.

Rehman, R. U., Chaudhary, M. F., Khawar, K. M., Lu, G., Mannan, A., and Zia, M. (2014). In vitro propagation of Caralluma tuberculata and evaluation of antioxidant potential. Biologia 69, 341-349. doi: 10.2478/s11756-013$0322-\mathrm{z}$
Sayes, C. M., Gobin, A. M., Ausman, K. D., Mendez, J., West, J. L., and Colvin, V. L. (2005). Nano-C60 cytotoxicity is due to lipid peroxidation. Biomaterials 26, 7587-7595. doi: 10.1016/j.biomaterials.2005.05.027

Schwambach, J., Fadanelli, C., and Fett-Neto, A. G. (2005). Mineral nutrition and adventitious rooting in microcuttings of Eucalyptus globulus. Tree Physiol. 25, 487-494. doi: 10.1093/treephys/25.4.487

Shier, W. T. (1994). Metals as toxins in plants. J. Toxicol. Toxin Rev. 13, 205-216. doi: 10.3109/15569549409089960

Sosan, A., Dimitri, S., Darya, S., Katsiaryna, T., Igor, S., Tracy, L., et al. (2016). Engineered silver nanoparticles are sensed at the plasma membrane and dramatically modify the physiology of Arabidopsis thaliana plants. Plant J. 85, 245-257. doi: $10.1111 /$ tpj. 13105

Stampoulis, D., Sinha, S. K., and White, J. C. (2009). Assay-dependent phytotoxicity of nanoparticles to plants. Environ. Sci. Technol. 43, 9472-9479. doi: $10.1021 / \mathrm{es} 901695 \mathrm{c}$

Stanisławski, J. J. (1977). Rola kwasu 3-indolilooctowego w procesach wzrostowych roślin [Role of IAA in plant growth]. Wiad. Bot. 21, 43-59.

Tanaka, M., Takei, K., Kojima, M., Sakakibara, H., and Mori, H. (2006). Auxin controls local cytokinin biosynthesis in the nodal stem in apical dominance. Plant J. 45, 1028-1036. doi: 10.1111/j.1365-313X.2006. 02656.x

Tsui, C. (1948). The role of zinc in auxin synthesis in tomato plants. Am. J. Bot. 35, 172-179. doi: 10.2307/2438240

Van Dongen, J. T., Ammerlaan, A. M. H., Wouterlood, M., Van Aelst, A. C. V., and Borstlap, A. C. (2003). Structure of the developing pea seed coat and the post-phloem transport pathway of nutrients. Ann. Bot. 91, 729-737. doi: $10.1093 / \mathrm{aob} / \mathrm{mcg} 066$

Van Ginneken, L., Meers, E., Guisson, R., Ruttens, A., Elst, K., Tack, F. M. G., et al. (2007). Phytoremediation for heavy metal-contaminated soils combined with bioenergy production. J. Environ. Eng. Landsc. Manag. 15, 227-236. doi: 10.1007/s10661-014-4247-y

Wierzbicka, M., and Obidzinska, J. (1998). The effect of lead on seed imbibitions and germination in different plant species. Plant Sci. 137, 155-171. doi: 10.1016/S0168-9452(98)00138-1

Wilson, M. R., Lightbody, J. H., Donaldson, K., Sales, J., and Stone, V. (2002). Interactions between ultrafine particles and transition metals in vivo and in vitro. Toxicol. Appl. Pharm. 184, 172-179. doi: 10.1006/taap.2002.9501

Zaka, M., Abbasi, B. H., Rahman, L., Shah, A., and Zia, M. (2016). Synthesis and characterization of metal nanoparticles and their effects on seed germination and seedling growth in commercially important Eruca sativa. IET Nanobiotehnol. doi: 10.1049/iet-nbt.2015.0039

Zhang, S., and Saebfar, H. (2010). Chemical Information Call-in Candidate: Nano Zinc Oxide. Ph.D. thesis, California Department of Toxic Substances Control, San Francisco, CA, 1-11.

Conflict of Interest Statement: The authors declare that the research was conducted in the absence of any commercial or financial relationships that could be construed as a potential conflict of interest.

Copyright $\odot 2016$ Zafar, Ali, Ali, Haq and Zia. This is an open-access article distributed under the terms of the Creative Commons Attribution License (CC BY). The use, distribution or reproduction in other forums is permitted, provided the original author(s) or licensor are credited and that the original publication in this journal is cited, in accordance with accepted academic practice. No use, distribution or reproduction is permitted which does not comply with these terms. 